\title{
Possible Biogeophysical Effects of Cultivated Land Conversion in Northeast China in 2010-2030
}

\author{
Haiming Yan, ${ }^{1}$ Jinyan Zhan, ${ }^{1}$ Juan Huang, ${ }^{1}$ and Tengteng Zhai ${ }^{2}$ \\ ${ }^{1}$ State Key Laboratory of Water Environment Simulation, School of Environment, Beijing Normal University, Beijing 100875, China \\ ${ }^{2}$ College of Public Administration, Nanjing Agricultural University, Nanjing 210095, China
}

Correspondence should be addressed to Jinyan Zhan; zhanjy@bnu.edu.cn

Received 29 August 2013; Revised 12 December 2013; Accepted 23 December 2013; Published 10 February 2014

Academic Editor: Burak Güneralp

Copyright (C) 2014 Haiming Yan et al. This is an open access article distributed under the Creative Commons Attribution License, which permits unrestricted use, distribution, and reproduction in any medium, provided the original work is properly cited.

\begin{abstract}
There will be substantial cultivated land change in China as the society strives to meet the growing food demands, which will greatly influence the future climate. This study analyzed the possible biogeophysical effects of cultivated land change on the climate in Northeast China during 2010-2030 on the basis of simulation with the Weather Research and Forecast (WRF) model. Scenario analysis was first carried out on the possible changing trends of cultivated land. Then the climate effects of the cultivated land change were analyzed on the basis of the simulation with the WRF model. The simulation results indicate that the total cultivated land area in Northeast China will decrease during 2010-2030, mainly converting into urban and built-up land and forests due to the urbanization and governmental policies. Besides, the cultivated land change will lead to the increase of the sensible heat flux in the regions where a lot of cultivated land will change into urban and built-up land, while it will make the latent heat flux increase in the regions where the cultivated land will be mainly converted into forests through influencing the evapotranspiration. All these results can provide theoretical support for implementing the future land management in Northeast China.
\end{abstract}

\section{Introduction}

Human activities are widely recognized as one of the major contributors to climate change, through both combustion of fossil fuels and land use activities [1], with the land use/cover change (LUCC) considered as the major influencing factor [2]. Many studies have revealed the extent to which land cover changes have affected local and regional and even global climate $[3,4]$. For example, some previous research suggests that human-induced conversion from forests to cultivated lands could lead to a cooling of $0.25^{\circ} \mathrm{C}$ on a global basis [5], and northern midlatitude agricultural regions are about $1-2^{\circ} \mathrm{C}$ cooler in the winter and spring compared to the preindustrial state due to replacement of forest by cultivated lands [6]. A lot of observations and simulation experiments have suggested that the LUCC at various scales has been the most important means through which the human activities influence the climate $[7,8]$, and therefore it is of great importance to study the influence of LUCC on the regional climate.
Improved understanding of how human activities influence climate is of great significance to guiding policies aiming at coping with or adapting to climate change [1]. The LUCC influences the climate at various scales through both biogeophysical and biogeochemical mechanisms [2, 9]. The biogeophysical mechanisms include the effects of changes in surface roughness and transpiration albedo and, for example, replacing forests with cultivated lands leads to an increase in the surface albedo [10]. The biogeochemical mechanisms, such as the forest conversion, can lead to large direct emissions of $\mathrm{CO}_{2}$ into the atmosphere, which in turn modifies the Earth's energy balance and influences the climate [11]. The change in land surface can result in emission or removal of $\mathrm{CO}_{2}$ to the atmosphere and influence the Earth's radiation balance; it can also alter the fluxes of sensible and latent heat to the atmosphere and consequently change the distribution of energy within the climate system and finally influence the climate at the local, regional, and even global scale [4]. However, most of current climate mitigation policies have seldom incorporated the effects of changes in 


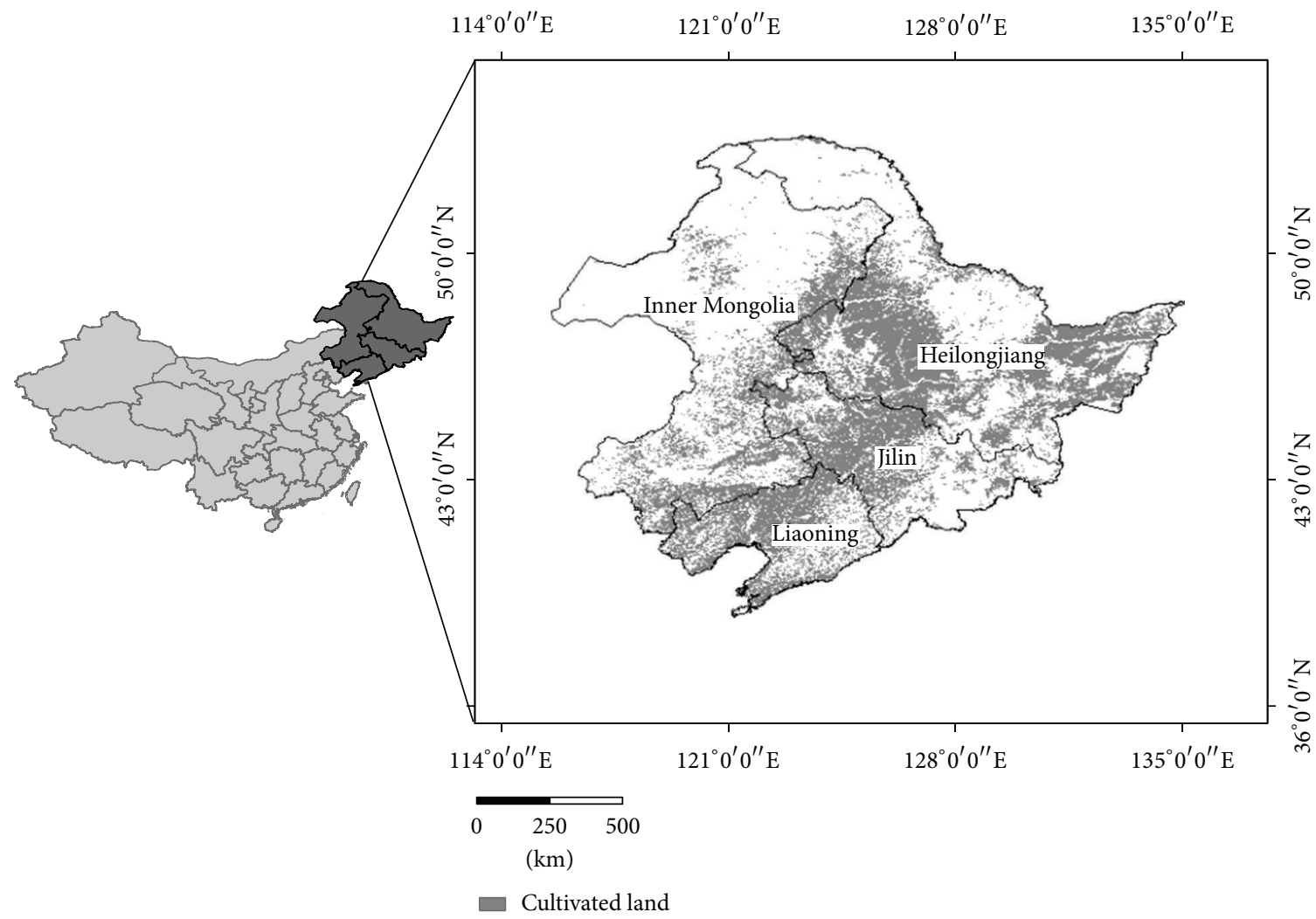

FIgURE 1: Location of Northeast China. Northeast China covers Heilongjiang Province, Jilin Province, Liaoning Province, and the northeast part of Inner Mongolia Autonomous Region.

the land surface on the surface albedo, the fluxes of sensible and latent heat to the atmosphere, and the distribution of energy within the climate system, all of which can affect the local, regional and global climate, and therefore these policies might lead to land management decisions that do not produce the intended climatic results [4]. Besides, a number of models have been used to study the impacts of LUCC on the climate, but most of them have not taken into account the geographically explicit changes in land surface characteristics associated with land cover changes [10]. In addition, there are many land use changes that are not reflected in land cover but can potentially influence climate, including both conversion and other modifications, for example, changes occurring within existing cultivated lands that have the potential to affect local and global climate $[1,7]$. What is more, scientific understanding and tools are increasingly becoming available to address the broader implications of land surface interactions within the climate system for national and international policies [12]. Therefore, it is necessary and plausible to implement more in-depth research on the effects of LUCC on the climate change with the geographically explicit tools.

China is the most populous country that needs a lot of cultivated land to meet the enormous demand of the large population for grain as well as the demand of rapid economic development for land resources. Northeast China, where there is a lot of cultivated land, is one of the grain production bases that play a key role in guaranteeing the food security and economic development of the whole country (Figure 1). The continuous population growth and accelerated economic development in Northeast China will further lead to more dramatic LUCC and consequently exert more significant impacts on the climate. In fact, the land use has changed drastically in this region after the economic reform that was initiated in the early 1980s. The area of high quality cultivated land has shrunk due to the growing land demand of the urban expansion and economic development in this region [13]. Meanwhile the regional climate in Northeast China has also changed due to the human activities, especially the land use change in the past decades [14]. For example, the temperature has risen throughout the past decades, which further led to the increased drought time, more dramatic precipitation fluctuation, decreased climate productivity, and more frequent climate-related disasters [14]. Besides, some previous research indicates that there is surely some correlation between the climate change and the large-scale LUCC in Northeast China in recent decades $[15,16]$. Therefore, it is of great importance to analyze the interaction between the LUCC and climate change to understand the impacts of LUCC on the grain production in Northeast China, especially since the land resource is indispensable to most essential human activities and provides the basis for agricultural and forest production, recreation and settlement, and so forth. In this study, the potential biogeophysical effects of cultivated 
land change were analyzed on the basis of the scenario analysis on the land use change and simulation of climate change with the Weather Research and Forecast (WRF) model.

\section{Data and Methodology}

The simulation was implemented based on the land cover data and forcing data under different scenarios. First, the scenario analysis was carried out on the future LUCC in Northeast China, which provides the time series underlying surface data for the simulation with the WRF model. Three scenarios of land use change were designed according to characters of socioeconomic development in the study area $[13,16]$, and the structural change of land use was simulated with the module of Agriculture and Land Use in the Global Change Assessment Model (GCAM), with the socioeconomic factors as the driving force. Thereafter the future spatial pattern of land cover during 2010-2030 was simulated with the Dynamics of Land Systems (DLS) model [17], and finally the climate effects of the land use change were analyzed based on simulation with the WRF model.

2.1. Scenario Design of Land Use Change. Three scenarios, including the Business as Usual (BAU) scenario, Rapid Economic Growth (REG) scenario, and Coordinated Environmental Sustainability (CES) scenario, were designed based on the historical trends of land cover change and the possible future trends of socioeconomic development [13]. This study selected the population, total factor productivity (TFP), gross domestic product (GDP), and national policy as the variables of socioeconomic development, the changing trends of which are different under different scenarios. The BAU scenario is mainly based on historical trends of the population growth and economic development $[13,16]$, which provides the reference to compare with other scenarios. It is assumed that the urbanization and industrialization will continue under the BAU scenario; TFP which is on behalf of the scientific and technological progress will develop following the historical development trend, and China's population will peak in the year 2030. The REG scenario and CES scenario were designed according to the main risks and adjustment directions of the medium and long-term development of China. The REG scenario assumes that the structural reform of industries would be smoothly carried out, the resource allocation and distribution of the industrial structure will be more reasonable, and the economy will develop more and more quickly. Under the CES scenario, the population growth rate is lower than that of BAU scenario, the urbanization rate is relatively lower, and population and GDP would increase with a lower rate. Finally, with the socioeconomic factors as the driving force, the structural change of land use under each scenario was simulated with the module of Agriculture and Land Use in GCAM. GCAM is a dynamic recursive model of the economy, energy sector, land use, and water linked to a climate model of intermediate complexity. It consists of four modules, that is, Edmonds-Reilly-Barnes model (ERB), Agriculture and Land use simulation model (AgLU), Model for the Assessment of Greenhouse-gas Induced Climate Change (MAGICC), and Regional Climate Change Scenario Generator (SCENGEN). GCAM is a Representative Concentration Pathway (RCP)-class model, it fully integrates the energy and agriculture systems with economic equilibrium in the energy and agriculture markets and can be used to simulate scenarios, policies, and emission targets from various sources.

2.2. Simulation with the DLS Model. This study simulated the spatial pattern of land cover change in the study area with the DLS model, which is a collection of programs that simulates pattern changes in land uses by conducting scenario analysis of the area of land use change [17]. The DLS model is a simulation model that is capable of integrating multiple data sources to simulate the dynamics of land systems. It can export a macroscopic map of land use by estimating the effects of driving factors of spatial pattern changes, formulating land use conversion rules and scenarios of land use change and simulating dynamic spatiotemporal processes of land use changes. It consists of four modules, including scenario analysis module, spatial regression module, the conversion rules module, and spatial analysis modules. The spatial regression module is used to identify the relationships between land uses and their influencing factors; the scenario analysis module of land use changes is used to analyze the demands of land uses at the regional level. Conversion rules module is used to express possibility and ease of a certain type of land transfer to another type of land on each grid cell. The spatial allocation module is used to allocate land use changes from a regional level to the disaggregated grid cells. The simulation with the DLS model includes four steps. First, the statistical relationship between the spatial distribution of land use types and the driving factors was analyzed at the regional and grid scales, and the key driving factors were extracted according to the effects of the natural environment and socioeconomic factors on the spatial patterns of regional land use. Then the changing trend of the selected key driving factors is predicted based on their historical characteristics and current status at the regional level. Thereafter a proper scenario is identified and used to foresee the balances between the supply and demand of land resources. Finally, the spatial allocation of land cover is implemented at the $1 \mathrm{~km} \times 1 \mathrm{~km}$ grid level and the spatial pattern map of land cover was generated.

2.3. Simulation with the WRF Model. The WRF model is a next-generation mesoscale model developed by a group of scientists from different institutes [18]. It consists of three parts, including preprocessing module of mode (WPS), main module of model (ARW), and assimilation module of mode and postprocessing tools of mode data (WRF-VAR). The ARW (Edition 3.3) was used to analyze the impacts of land use/cover change on the land surface heat flux in this study. This study calculates the flux of momentum, sensible heat, latent heat and radiation, and so forth between the land surface and the atmosphere from the perspective of the water balance and energy balance with the WRF model based on 
the Noah land surface parameterization scheme and focused on the analysis of the sensible heat flux and latent heat flux to reveal the impacts of the future land use change on the regional climate change.

The land net radiation is the energy source of near-surface temperature change, and the latent heat flux and sensible heat flux are two key components of the land surface energy balance. Both of them are closely related with the efficient energy of the land surface and are influenced by the land surface characteristics and soil water and heat conditions. Besides, under the condition of certain land surface net radiation the underlying surface influences the temperature through influencing the sensible heat flux, latent heat flux, and soil heat flux $[6,7]$ :

$$
R_{n}=H+L E+G
$$

where $R_{n}$ is the land surface net radiation, $H$ is the sensible heat flux, $L E$ is the latent heat flux, and $G$ is the soil heat flux.

The land surface net radiation heavily depends on the sensible heat flux and latent heat flux since there is generally very limited heat flux into soil, and the underlying surface can directly influence the latent heat flux and consequently indirectly influence the near-surface temperature. Therefore, this study has mainly focused on the influence of land use change on the latent heat flux and sensible heat flux. Since the temperature is generally very low in the spring and winter in Northeast China, this study has only calculated the sum of the latent heat flux and sensible heat flux in the summer and autumn.

The parameterization scheme of the WRF model in this study includes the Noah land surface parameterization scheme, CAM3 radiation scheme, WSM3-class simple ice microphysics (MP) scheme, Grell-Devenyi ensemble scheme for cumulus convection, and YSU boundary layer scheme. The data of the lateral and boundary conditions came from the National Centers for Environmental Prediction global final analyses datasets (NCEP/FNL), being updated every 6 hours. This dataset has been constructed and updated since July of 1999 with the data assimilation of almost all kinds of observation data (e.g., the remote sensing data and ground-based observation data), and it has the spatial resolution of $1^{\circ} \times 1^{\circ}$ and the vertical height of 27 layers. The NCEP/FNL dataset has higher accuracy and spatial resolution and includes more kinds of environmental variables than the datasets of NCEP I, NCEP II, and EAR40. In addition, the land surface parameters in the WRF model under different conditions of land cover were adjusted according to the result of scenario analysis of the future land use change.

The simulation scheme in this study is as follows. The land cover dataset of year 2010 with the United States Geological Survey's (USGS) classification system was used as the baseline underlying surface data in this study. Then the structural change of land use in year 2010 and 2030 under different scenarios was simulated with the module of GCAM and the future spatial pattern of land cover was simulated with the DLS model. Furthermore, the land use data were used as the input underlying surface data of the WRF model to simulate the impacts of land cover change on the climate change.
Finally, the monthly and seasonal simulation results were compared as follows. Firstly, the simulation results of monthly temperature in year 2010 were used to validate the ability of the WRF model to simulate the temperature change in the study area; then spatial difference between the land surface heat flux in the winter of year 2010 and 2030 was analyzed; finally the policy implication of the results for the land use management was discussed.

2.4. Data and Processing. The input data of the WRF model mainly include the underlying surface data and climate forcing data. The $1 \mathrm{~km}$ resolution land cover data of the USGS classification system in year 2010 were used as baseline data, which were derived from the dataset of the National Key Programme for Developing Basic Science in China (973 Program, number 2010CB950900). These data were extracted from Landsat TM/ETM images, the interpretation accuracy of which exceeds $92 \%[19,20]$. The land use/cover data in the year 2020 and 2030 were predicted with the data of land conversion among land cover types. Since different communities have different classification systems for the land cover data, this study used the USGS classification which includes 24 land cover types. First, the $1 \mathrm{~km}$ resolution land cover data of USGS classification in year 2010 were extracted from the remote sensing images and were used as the land cover data in the baseline year. Then the land conversion data, which are used to forecast the land use change (land conversion among different land cover types) during 20102030, were simulated with the DLS model based on the different scenarios designed according to the land demand. Finally, the $1 \mathrm{~km}$ resolution land cover data were converted into the $10 \mathrm{~km}$ resolution data according to the requirement of the WRF model.

The forcing data needed in the WRF model include the wind field, surface air temperature, long-wave radiation, and short-wave radiation. This study used the climate forcing data from the NCEP/FNL Operational Global Analysis data, which were updated every 6 hours. This dataset has been constructed and updated since July of 1999 with the data assimilation of the remote sensing data and ground-based observation data and so forth. The static land surface data were the GEOG data provided by the WRF model, which were replaced with the land use/cover data under different scenarios in the further simulation. This study has used the Noah land surface parameterization scheme, with which the simulation result is more stable and reasonable. The data of the temperature field and precipitation field in this scheme were interpolated with the large scale information.

\section{Results and Discussion}

3.1. Cultivated Land Change under Different Scenarios. The simulation results indicate that the land use change in Northeast China during 2010-2030 is mainly characterized by the conversion from cultivated land into forests or urban and built-up land under the three scenarios, and the total cultivated land area will show a decreasing trend (Figure 2). The land use change will follow the historical trend under 


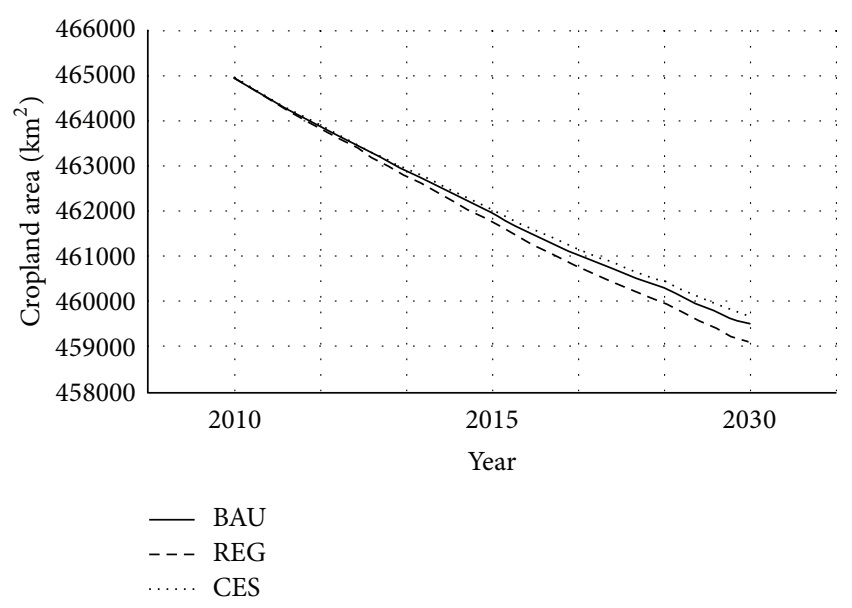

Figure 2: Changing trends of total cultivated land area in Northeast China during 2010-2030 under the three scenarios.

the BAU scenario; the cultivated land will mainly change into urban and built-up land and forests, the newly increased area of which will reach approximately $3782 \mathrm{~km}^{2}$ and $1471 \mathrm{~km}^{2}$ by 2030 , respectively. Besides, a few water bodies will be converted into cultivated land under the BAU scenario. By comparison, there will be more cultivated land converted into urban and built-up land under the REG scenario and forests under the CES scenario, the newly increased area of which reach $1889 \mathrm{~km}^{2}$ and $3798 \mathrm{~km}^{2}$, respectively. In addition, the cultivated land change will show significant spatial heterogeneity under the three scenarios. The conversion from cultivated land into forests mainly appears in the southern part of Heilongjiang Province, southern and middle part of Jilin Province, and southern and eastern part of Liaoning Province. While the conversion from cultivated land into urban and built-up land will mainly appear in the southern and eastern part of Liaoning Province, middle part of Jilin Province, and eastern part of Heilongjiang Province. What is more, compared to the BAU scenario, more cultivated land will be converted in to urban and built-up land in the regions around cities under the REG scenario, while more cultivated land will change in forests in the regions far from cities under the CES scenario, especially in some important water conservation area such as Three River Plain and Changbai Mountains.

The land use change in Northeast China is greatly influenced by the socioeconomic activities, with the conversion from cultivated land into forests and urban and built-up mainly driven by the governmental policies, socioeconomic development, and urbanization. For example, a series of major ecological construction projects have been implemented, for example, Three-North Forest Shelterbelt Program and Green for Grain Project, all of which greatly promoted the expansion of the forests in Northeast China. For example, a lot of mixed dryland/irrigated cultivated land has been converted into grassland or mixed forests in the northeast part of Inner Mongolia Autonomous Region, middle and eastern parts of Heilongjiang Province, and Jilin
Province; the vegetation degradation in Northeast China has been under control to some degree. Besides, the urban land expansion has led to the occupation of cultivated land around the cities. The simulation results also suggest that more cultivated land around the metropolis and small cities will be occupied since the socioeconomic development leads to more demand for land resources. In summary, under the influence of urbanization and governmental policies, the spatial heterogeneity of cultivated land reclamation and occupation will lead to more obvious spatial heterogeneity of cultivated land, which will exert significant impacts on the regional climate.

\subsection{Influence of the Future Cultivated Land Change on the} Land Surface Energy Balance. The simulation under the three scenarios all indicate that the average latent heat flux in Northeast China will show a decreasing trend, while the average sensible heat flux will show an increasing trend, but both of them show some spatial heterogeneity (Figure 3). Compared to 2010, the latent heat flux in 2030 will decrease by $0.05-0.07 \mathrm{~W} / \mathrm{m}^{2}$ on average and show a decreasing trend on average. The latent heat flux will decrease slightly in most part of the study area. It will decrease significantly in only a few regions, such as the western part of Jilin Province and southern part of Heilongjiang Province, where a lot of cultivated land will change into urban and built-up land, with a decrement of approximately $10 \mathrm{~W} / \mathrm{m}^{2}$ on average. While the latent heat flux will increase in the northeast part of Inner Mongolia Autonomous Region and the eastern boundary regions of Heilongjiang Province and Jilin Province, where the cultivated lands occupy a large fraction of the total land area, and the cultivated land will mainly be converted into forests.

The sensible heat flux in 2030 shows an increasing trend on the whole compared to that in 2010, with the average value increasing by $0.06-0.07 \mathrm{~W} / \mathrm{m}^{2}$ (Figure 4 ). The simulation result indicates that the sensible heat flux will increase slightly in most part of the study area, with the increment of approximately $0.3 \mathrm{~W} / \mathrm{m}^{2}$. The simulation results under the three scenarios suggest that the sensible heat flux will increase in the northern part of Great Khingan Mountains and Lesser Khingan Mountains, where a lot of cultivated land will change into urban and built-up land, while it will increase most slightly in Liaohe Plain, Liaodong Peninsula and southern part of Changbai Mountains, where the cultivated land will mainly change into forests or grassland and the decreased albedo will substantially increase the evaporative flux. In summary, in the regions of returning cultivated land to forests, the forest expansion will increase the evapotranspiration, increase the latent heat flux, decrease the sensible heat flux, and consequently lead to the decrease of the nearsurface temperature [21]. On the other hand, in the regions of urbanization, the decrease of evapotranspiration due to conversion from cultivated land into urban and built-up land will lead to significant decrease of latent heat flux and obvious increase of sensible heat flux, which is the main cause of the near-surface temperature rise [22]. 


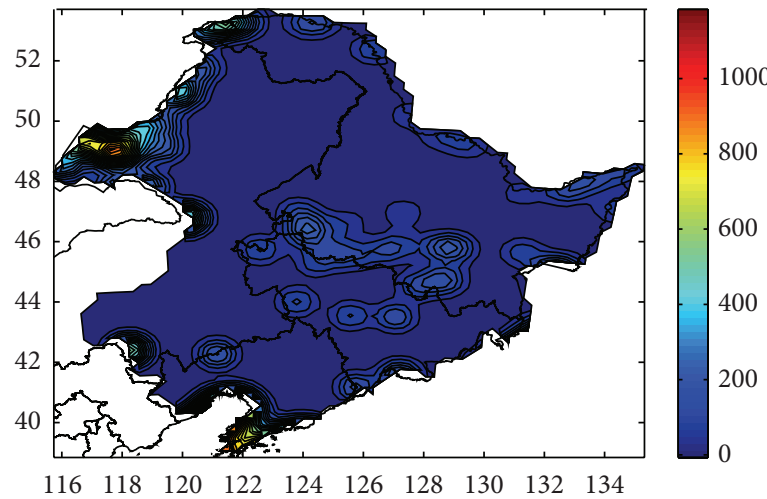

(a)

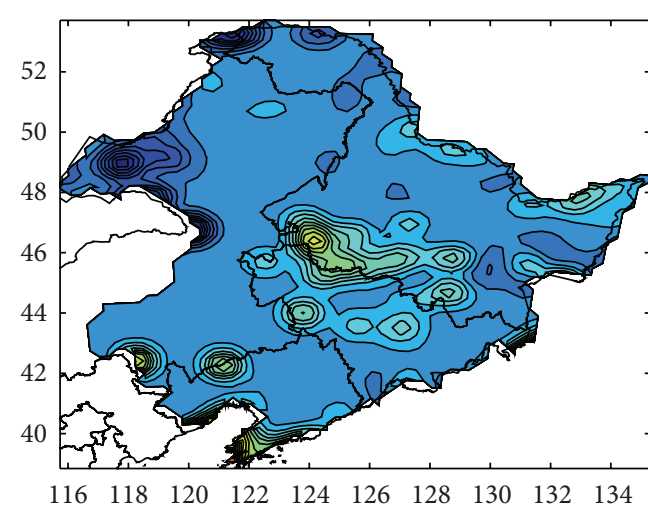

(c)

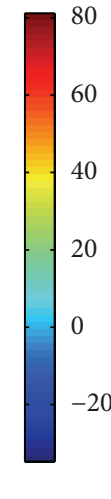

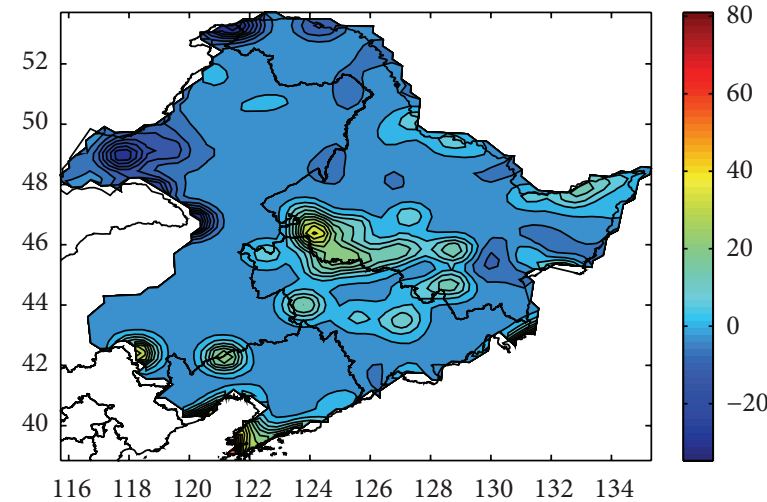

(b)

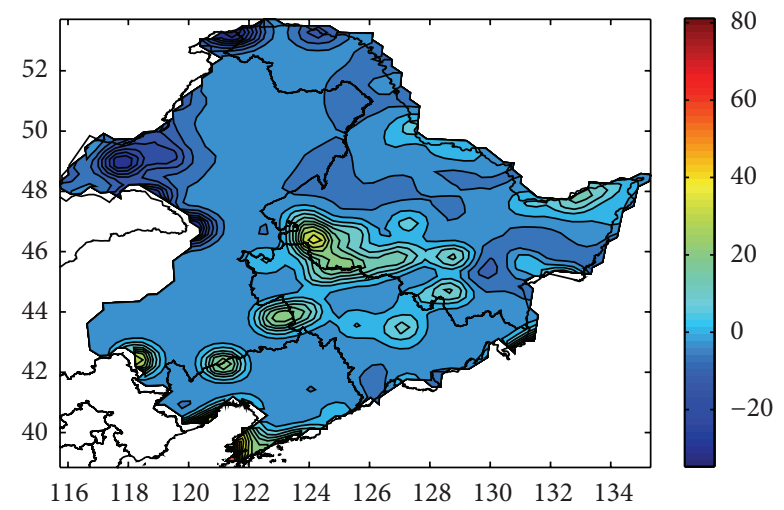

(d)

Figure 3: Difference between the latent heat flux in Northeast China in 2010 and 2030 under different scenarios (unit: W/m²). (a) Spatial pattern of the latent heat flux in 2010; (b) difference of the latent heat flux between 2010 and 2030 under the BAU scenario; (c) difference of the latent heat flux between 2010 and 2030 under the REG scenario; (d) difference of the latent heat flux between 2010 and 2030 under the CES scenario.

The difference in the change of the latent heat flux and sensible heat flux under the three scenarios is mainly due to the difference in cultivated land change. The simulation results in this study suggest that more cultivated land will be converted into urban and built-up land in the regions around cities under the REG scenario, while more cultivated land will be converted into forests in the regions far from cities under the CES scenario. All these conversions will cause obvious vegetation cover change, which will further lead to significant spatial heterogeneity of the latent heat flux and sensible heat flux. The result indicates that the latent heat flux increases the most obviously in the regions where the cultivated land mainly converts into forests, while the sensible heat flux increases the most obviously in the regions where the cultivated land mainly converts into urban and builtup land in Northeast China. A lot of research has indicated that the terrestrial vegetation cover change can influence the land surface energy budget through altering the land surface albedo, roughness, and so forth and consequently change the precipitation and temperature. In Northeast China, the conversion from cultivated land into nonagricultural land has been the main reason for the soil moisture change in regions around cities. The irrigation in irrigated cultivated land can increase the latent heat flux and decrease sensible heat flux and consequently have cooling effects on the land surface. However, the conversion from irrigated cultivated land into urban and built-up land has greatly weakened this cooling effect since it decreases the land surface roughness and increases the land surface albedo, which leads to the decrease of evapotranspiration as well as the land surface net radiation and consequently decreases the latent heat flux and increases the sensible heat flux. What is more, returning cultivated land to forests plays a positive role in restoring the soil water environment, and afforestation can significantly increase the solar radiation absorbed by the land surface, making the evapotranspiration increase, which will increase the latent heat flux and decrease the sensible heat flux, and consequently decrease the temperature. In fact, the land use has changed greatly due to the urbanization, returning cultivated land into forests and so forth in Northeast China in the past decades, leading to more significant spatial heterogeneity of cultivated land, which further leads to spatial heterogeneity of impacts of land use on the climate.

It is still necessary to carry out more in-depth research in the future in order to forecast the possible climate effects of land use change more accurately, and it is also necessary to 


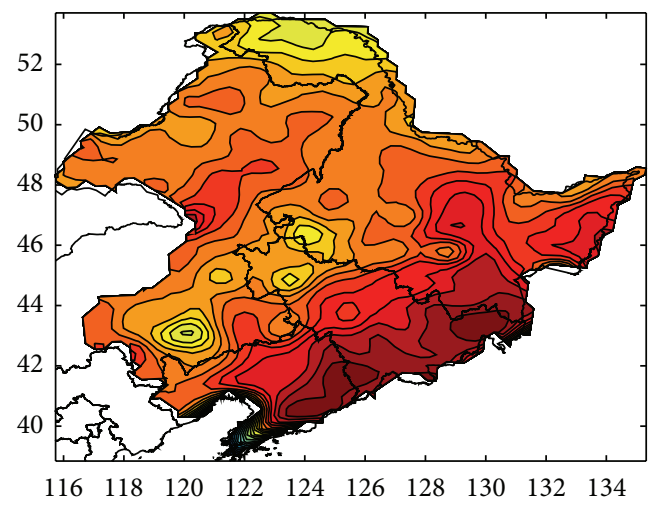

(a)

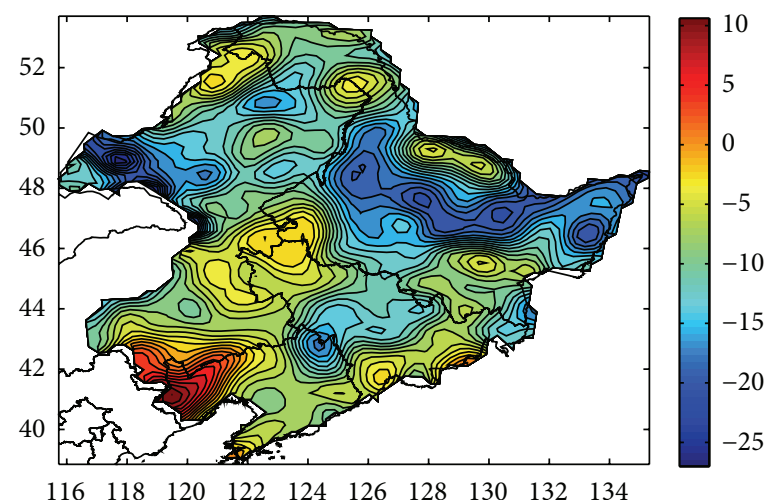

(c)

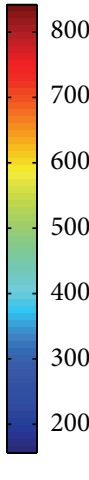

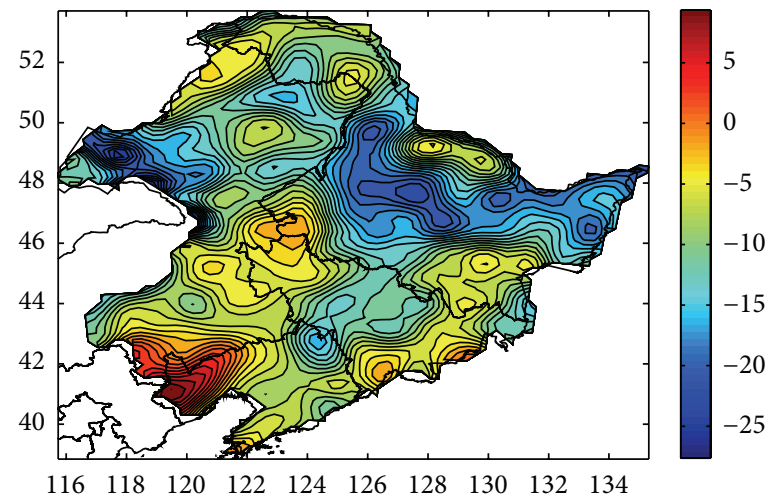

(b)

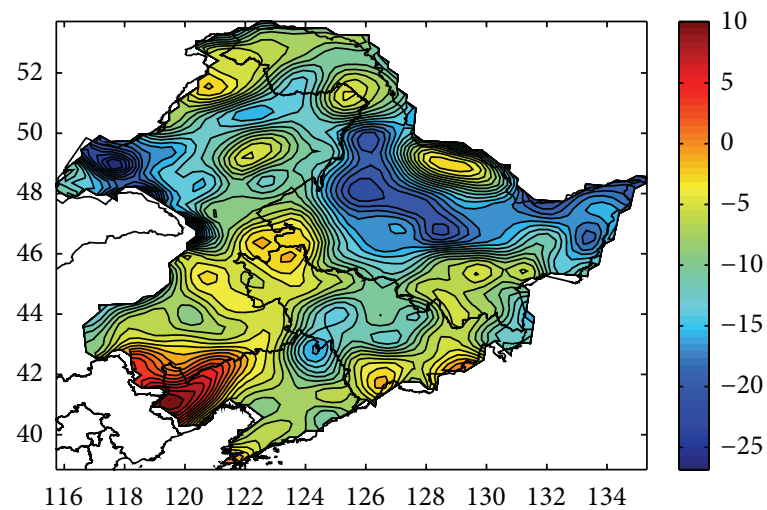

(d)

Figure 4: Difference between the sensible heat flux in Northeast China in 2010 and 2030 under different scenarios (unit: W/m²). (a) Spatial pattern of the sensible heat flux in 2010; (b) difference of the sensible heat flux between 2010 and 2030 under the BAU scenario; (c) difference of the sensible heat flux between 2010 and 2030 under the REG scenario; (d) difference of the sensible heat flux between 2010 and 2030 under the CES scenario.

quantitatively analyze the changing trends of the temperature and precipitation and comprehensively take into account the future changes of the monsoon, general atmospheric circulation, change of other land use types, and so on in the future research. For example, the regional climate change is influenced by various factors, including not only the human activities, but also the natural factors such as the solar activity, all of which should be involved in the further studies. Although there are some uncertainties in the simulation result in this study, it still can provide scientific support for the land managers to regulate and control the land use more reasonably.

3.3. Policy Implication for the Land Use Management. Human activities have contributed to anthropogenic climate change through a variety of processes, including both of the growth or degradation of surface vegetation and the changes in the land surface; however, impacts of the latter one are not currently being incorporated into the development of climatechange mitigation policies [4]. For example, some previous studies have quantified the potential of crop management changes to sequester greenhouse gases, but the biogeophysical effects of most management changes have been less widely considered [1]. The cultivated land change in Northeast China is directly caused by the human activities [21], and the land use management can exert great influence on the cultivated land change, especially the conversion between the cultivated land and other land use types, which will further influence the climate change. The population growth is still the fundamental reason for the expansion of cultivated land in Northeast China; the economic development and the macropolicy are important driving factors of the land use change. With the rapid economic development and accelerated urbanization, more cultivated land will be converted into urban and builtup land [23, 24]. Meanwhile, with more attention paid to the environmental protection, some cultivated land will also be returned to forests, especially in Northeast China, where there were once a lot of forests converted into cultivated land due to the population growth and improper land management. Therefore, there will surely be more demand for the land resources as the population continually increases and the economy rapidly develops in Northeast China, which will lead to further land use change and subsequently exert more influence on the regional climate.

It is of great significance to explore how the human activities influence climate to guiding policies to mitigate or 
adapt to climate change since the land use management can exert great influence on the land use change and subsequently influence the regional climate change $[4,25]$. Over the past several centuries, human intervention has markedly impacted land surface characteristics as well as atmospheric composition in Northeast China, in particular through largescale land conversion for cultivation and burning of fossil fuels $[10,26]$. The land use change in Northeast China influences the climate change through not only the expansion of agriculture into natural ecosystems, but also the changes occurring within existing cultivated land. For example, historical clearing of forests for cultivated land is likely to have a cooling effect due to the greater albedo of cultivated land relative to forests $[25,27]$. Besides, the increases in irrigation and reductions in tillage all have a physical cooling effect through increasing the planetary albedo [22, 28]. In addition, some research showed how reforestation in the temperate and boreal zones can also lead to a net warming, with the biogeophysical (snow-albedo feedback) exceeding biogeochemical effects, thereby accelerating rather than mitigating climate change [10]. However, more information on the sensitivity of climate to these management changes is needed to identify the climate-related tradeoffs associated with future policy and management decision [1]. In summary, more attention should be paid to LUCC since it is one of the most important ways the human activities influence the climate change, and more in-depth research should be carried out on the climate effects of LUCC since there are still some uncertainties in current research results.

More rational land use management measures should be implemented according to the local conditions of the study area in order to reduce the adverse climate effects of land use change while striving to meet the land demand of economic development. For example, it is necessary to control the loss of forests during the land reclamation in order to fulfill their role in regulating the climate and preventing water and soil erosion in Northeast China. It is urgent to improve the forest management to minimize the loss of existing forests in order to minimize human-induced climate change at all scales. Meanwhile more efforts should be made to restore the structures and functions of native ecosystems to minimize the human impacts on the climate system. Besides, it is feasible to alleviate the climate change through returning cultivated land to forests or grassland, and it is necessary to further implement the ecological construction projects such as the Project of Three North Shelterbelt. In addition, it is feasible to promote management changes such as reduced tillage and increased irrigation in consideration of their climate effects, and management practices that demonstrably mitigate regional or global climate change might be encouraged through incentives to farmers [25].

\section{Conclusions}

This study analyzed the potential climate effects of cultivated land change in Northeast China during 2010-2030 based on the scenario analysis on the land use change and the simulation with the WRF model. The simulation results indicate that the land use change in Northeast China will be mainly characterized by the conversion from cultivated land into forests and urban and built-up land during 20102030, with the total cultivated land area showing a decreasing trend, which will inevitably influence the regional climate. Besides, the result of the simulation with the WRF model indicated that average latent heat flux in the whole Northeast China would show a decreasing trend during 2010-2030 under the three scenarios, while the average sensible heat flux will show an increasing trend. In addition, there is significant spatial heterogeneity in the change of both the latent heat flux and sensible heat flux. The latent heat flux will decrease slightly in most part of the study area, but it will decrease the most obviously in some regions where a lot of cultivated land will change into urban and built-up land, while it will increase the most obviously in some part of the study area where the cultivated land will mainly change into forests. By comparison, the sensible heat flux will show an increasing trend on the whole during 2010-2030, the simulation results under the three scenarios suggest that it will increase the most obviously in the northern part of Great Khingan Mountains and Lesser Khingan Mountains, where a lot of cultivated land will change into urban and built-up land, while it will increase most slightly in the regions where the cultivated land will mainly change into forests or grassland. Although there are some uncertainties in the simulation result, it still can provide some useful information for the land managers to regulate the land use more scientifically.

\section{Conflict of Interests}

The authors declare that there is no conflict of interests regarding the publication of this paper.

\section{Acknowledgments}

This research was supported by the National Key Programme for Developing Basic Science in China (no. 2012CB955700 and no. 2010CB950900) and the Key Project in the National Science \& Technology Pillar Program of China (no. 2013BAC03B00). Data support from the projects funded by the Chinese Academy of Sciences (KZZD-EW-08; GJHZ1312) and Exploratory Forefront Project for the Strategic Science Plan in IGSNRR, CAS, is also greatly appreciated.

\section{References}

[1] D. B. Lobell, G. Bala, and P. B. Duffy, "Biogeophysical impacts of cropland management changes on climate," Geophysical Research Letters, vol. 33, no. 6, Article ID L06708, 2006.

[2] R. A. Betts, "Biogeophysical impacts of land use on presentday climate: near-surface temperature change and radiative forcing," Atmospheric Science Letters, vol. 2, no. 1-4, pp. 39-51, 2001.

[3] M. Claussen, V. Brovkin, and A. Ganopolski, "Biophysical versus biogeochemical feedbacks of large-scale land cover change," Geophysical Research Letters, vol. 28, no. 6, pp. 1011-1014, 2001.

[4] G. Marland, R. A. Pielke Sr., M. Apps et al., "The climatic impacts of land surface change and carbon management, and 
the implications for climate-change mitigation policy," Climate Policy, vol. 3, no. 2, pp. 149-157, 2003.

[5] B. Govindasamy, P. B. Duffy, and K. Caldeira, "Land use changes and Northern Hemisphere cooling," Geophysical Research Letters, vol. 28, no. 2, pp. 291-294, 2001.

[6] R. A. Betts, P. D. Falloon, K. K. Goldewijk, and N. Ramankutty, "Biogeophysical effects of land use on climate: model simulations of radiative forcing and large-scale temperature change," Agricultural and Forest Meteorology, vol. 142, no. 2-4, pp. 216233, 2007.

[7] J. J. Feddema, K. W. Oleson, G. B. Bonan et al., "Atmospheric science: the importance of land-cover change in simulating future climates," Science, vol. 310, no. 5754, pp. 1674-1678, 2005.

[8] R. Mahmood, S. A. Foster, T. Keeling, K. G. Hubbard, C. Carlson, and R. Leeper, "Impacts of irrigation on 20th century temperature in the northern Great Plains," Global and Planetary Change, vol. 54, no. 1-2, pp. 1-18, 2006.

[9] S. Gibbard, K. Caldeira, G. Bala, T. J. Phillips, and M. Wickett, "Climate effects of global land cover change," Geophysical Research Letters, vol. 32, no. 23, Article ID L23705, 2005.

[10] S. Sitch, V. Brovkin, W. von Bloh, D. van Vuuren, B. Eickhout, and A. Ganopolski, "Impacts of future land cover changes on atmospheric $\mathrm{CO}_{2}$ and climate," Global Biogeochemical Cycles, vol. 19, no. 2, Article ID GB2013, pp. 1-15, 2005.

[11] A. D. McGuire, S. Sitch, J. S. Clein et al., "Carbon balance of the terrestrial biosphere in the twentieth century: analyses of $\mathrm{CO}_{2}$, climate and land use effects with four process-based ecosytem models," Global Biogeochemical Cycles, vol. 15, no. 1, pp. 183-206, 2001.

[12] X. Z. Deng, C. H. Zhao, and H. Y. Yan, "Systematic modeling of impacts of land use and land cover changes on regional climate: a review," Advances in Meteorology, vol. 2013, Article ID 317678, 11 pages, 2013.

[13] L. Jiang, X. Z. Deng, and K. C. Seto, "Multi-level modeling of urban expansion and cultivated land conversion for urban hotspot counties in China," Landscape and Urban Planning, vol. 108, no. 2-4, pp. 131-139, 2012.

[14] M. L. Liu, H. Q. Tian, G. S. Chen, W. Ren, C. Zhang, and J. Y. Liu, "Effects of land-use and land-cover change on evapotranspiration and water yield in China during 1900-2000," Journal of the American Water Resources Association, vol. 44, no. 5, pp. 1193-1207, 2008.

[15] Y. H. Ding and X. S. Dai, "Temperature variation in China during the last 100 years," Meteorological Monthly, vol. 12, no. 1, pp. 19-26, 1994.

[16] J. H. Liu, J. X. Gao, B. Geng, and L. J. Wu, "Study on the dynamic change of land use and landscape pattern in the farmingpastoral region of Northern China," Research of Environmental Sciences, vol. 20, no. 5, pp. 148-154, 2007.

[17] X. Z. Deng, H. B. Su, and J. Y. Zhan, "Integration of multiple data sources to simulate the dynamics of land systems," Sensors, vol. 8, no. 2, pp. 620-634, 2008.

[18] M. A. Hernandez-Ceballos, J. A. Adame, J. P. Bolivar, and B. A. de la Morena, "A mesoscale simulation of coastal circulation in the Guadalquivir valley (southwestern Iberian Peninsula) using the WRF-ARW model," Atmospheric Research, vol. 124, pp. 1-20, 2013.

[19] J. Y. Liu, Z. X. Zhang, X. L. Xu et al., "Spatial patterns and driving forces of land use change in China during the early 21st century," Journal of Geographical Sciences, vol. 20, no. 4, pp. 483-494, 2010.
[20] F. Wu, J. Y. Zhan, H. M. Yan, C. C. Shi, and J. Huang, "Land cover mapping based on multisource spatial data mining approach for climate simulation: a case study in the farming-pastoral ecotone of North China," Advances in Meteorology, vol. 2013, Article ID 520803, 12 pages, 2013.

[21] X. Z. Deng, Q. O. Jiang, J. Y. Zhan, S. J. He, and Y. Z. Lin, "Simulation on the dynamics of forest area changes in Northeast China," Journal of Geographical Sciences, vol. 20, no. 4, pp. 495509, 2010.

[22] J. Y. Liu and X. Z. Deng, "Impacts and mitigation of climate change on Chinese cities," Current Opinion in Environmental Sustainability, vol. 3, no. 3, pp. 188-192, 2011.

[23] X. Z. Deng, J. Huang, S. Rozelle, and E. Uchida, "Economic growth and the expansion of urban land in China," Urban Studies, vol. 47, no. 4, pp. 813-843, 2010.

[24] L. Jiang, X. Z. Deng, and K. C. Seto, "The impact of urban expansion on agricultural land use intensity in China," Land Use Policy, vol. 35, pp. 33-39, 2013.

[25] N. Lehmann, S. Briner, and R. Finger, "The impact of climate and price risks on agricultural land use and crop management decisions," Land Use Policy, vol. 35, pp. 119-130, 2013.

[26] J. Y. Liu and X. Z. Deng, "Influence of different land use on urban microenvironment in Beijing City, China," Journal of Food, Agriculture and Environment, vol. 9, no. 3-4, pp. 1005-1011, 2011.

[27] X. Z. Deng, Q. O. Jiang, H. B. Su, and F. Wu, "Trace forest conversions in Northeast China with a 1-km area percentage data model," Journal of Applied Remote Sensing, vol. 4, no. 1, Article ID 041893, 2010.

[28] Q. L. Shi, Y. Z. Lin, E. P. Zhang, H. M. Yan, and J. Y. Zhan, "Impacts of cultivated land reclamation on the climate and grain production in Northeast China in the future 30 years," Advances in Meteorology, vol. 2013, Article ID 853098, 8 pages, 2013. 

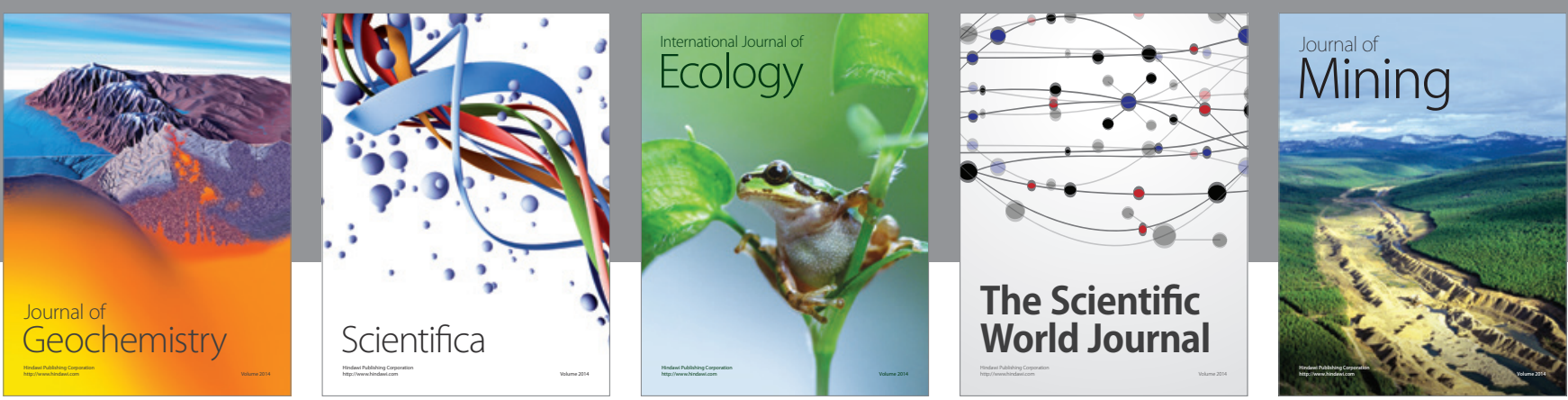

The Scientific World Journal
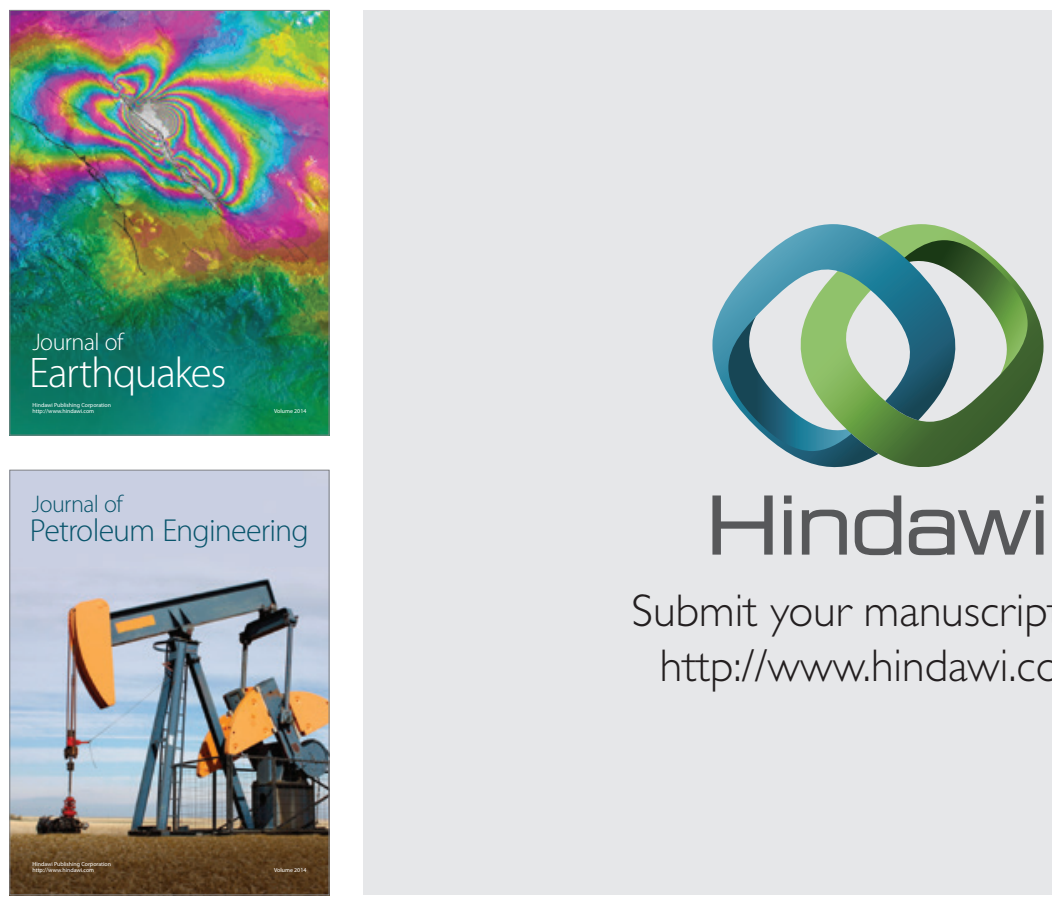

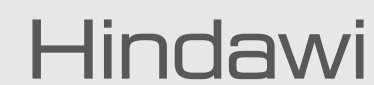

Submit your manuscripts at

http://www.hindawi.com
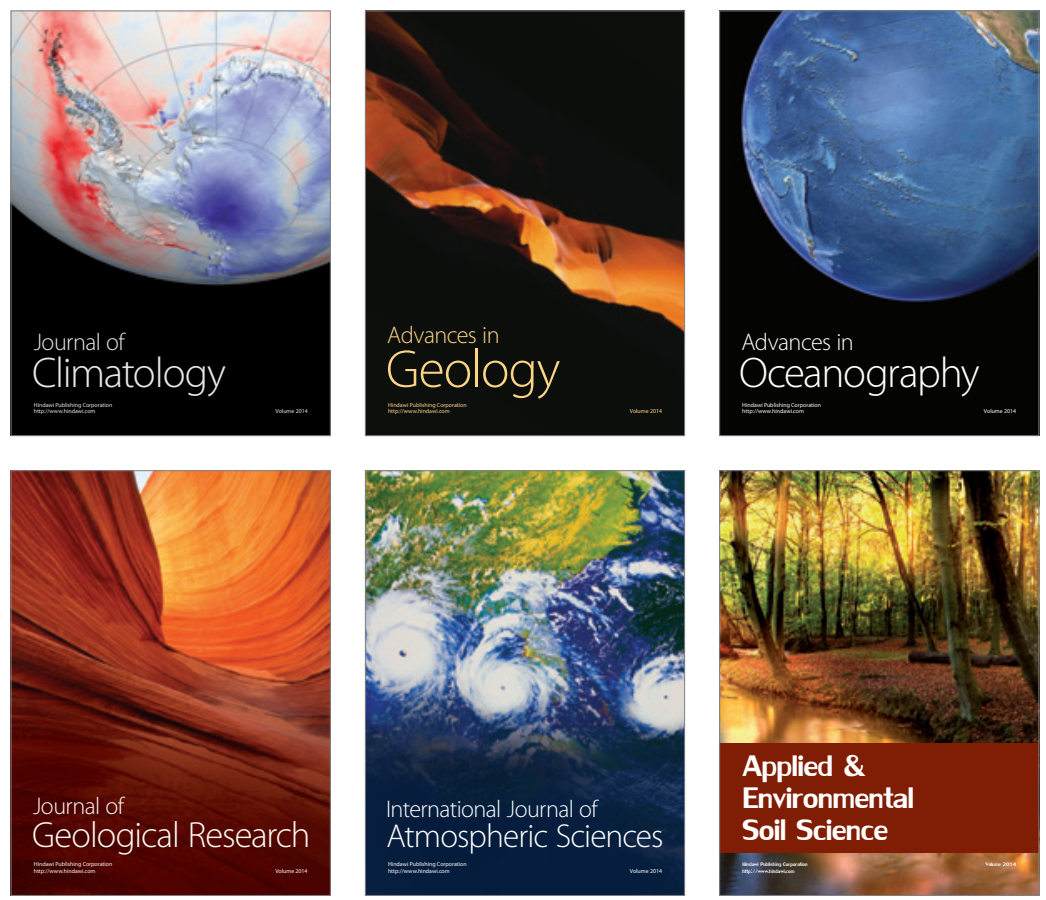
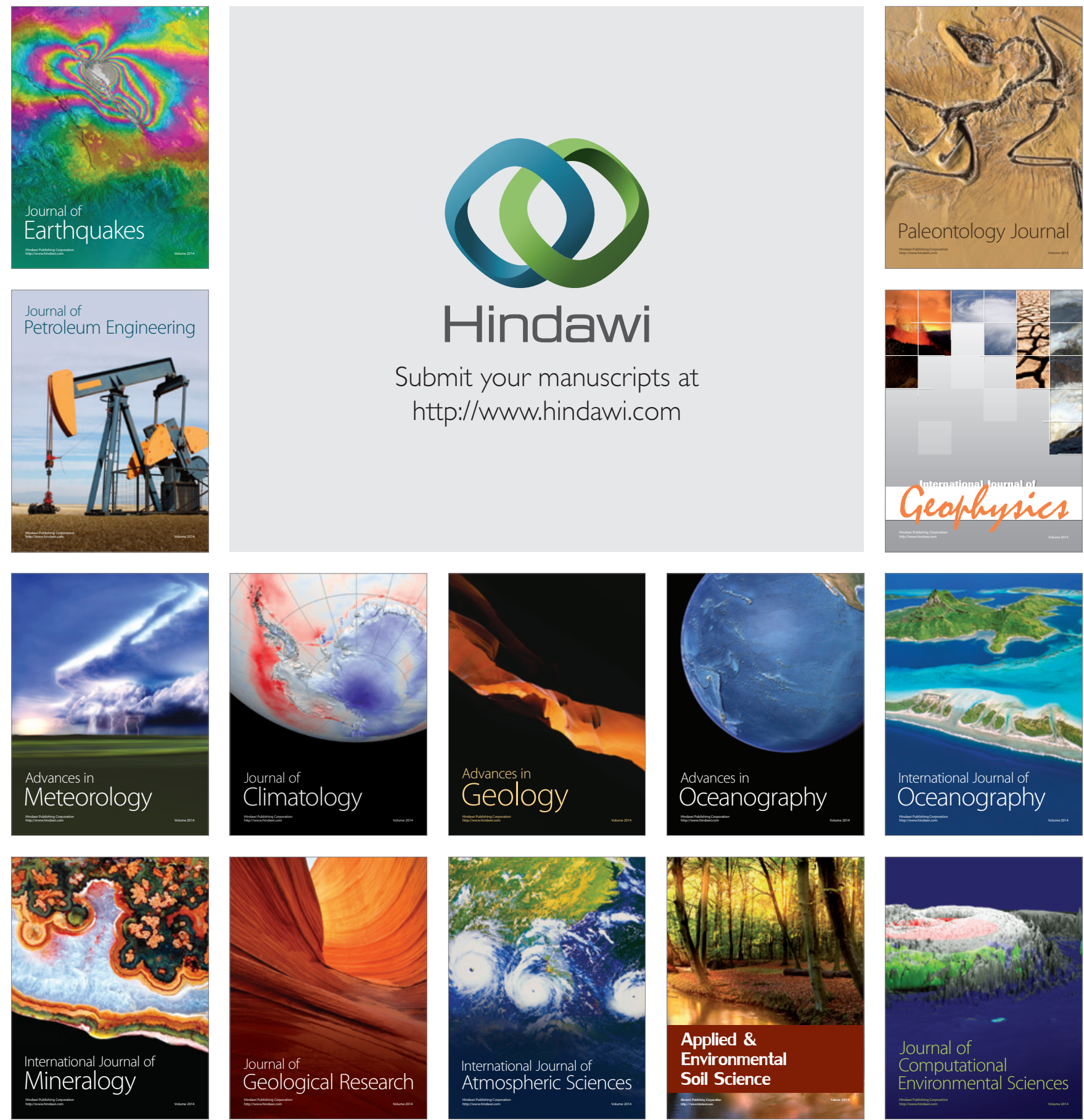